\title{
DESCRIÇÃO, CONSTITUIÇÃO E ASPECTOS ASSOCIADOS À FORMAÇÃO DOS FETOS Perosomus elumbis
}

\author{
Renan Guilherme Mota ${ }^{1^{*}}$ \\ Eudes Esteves do Nascimento ${ }^{2}$ \\ Hiago Cortezini Hadid ${ }^{1}$
}

\begin{abstract}
MOTA, R. G.; NASCIMENTO, E. E. do; HADID, H. C. Descrição, constituição e aspectos associados à formação dos fetos Perosomus elumbis. Arq. Ciênc. Vet. Zool. UNIPAR, Umuarama, v. 19, n. 2, p. 121-124, abr./jun. 2016.
\end{abstract}

\begin{abstract}
RESUMO: O feto Perosomus elumbis está inserido num vasto grupo de doenças congênitas raras e de etiologias desconhecidas dentro da medicina veterinária. Por ser de baixa ocorrência, e de difícil acesso e investigação científica, há dificuldade em realizarem-se estudos e conclusões sobre a doença. Com sobrevida máxima de dois dias, sendo a maioria dos fetos natimortos, a anomalia caracteriza-se principalmente por agenesia (ausência ou formação incompleta de um órgão) parcial da medula espinhal, terminando em fundo cego nas últimas vértebras torácicas, e ausência de vértebras lombares, sacrais e coccígeas, convergindo para anomalias secundárias que envolvem artrogripose (flexão ou contratura congênita de uma articulação), atrofia muscular de membros pélvicos e outras malformações subsequentes. Observa-se também a possibilidade de ocorrer anormalidades congênitas concomitantemente à formação desses fetos.
\end{abstract}

PALAVRAS-CHAVE: Agenesia. Congênita. Malformação. Medula espinhal.

\section{DESCRIPTION, COMPOSITION AND ASPECTS ASSOCIATED WITH THE FORMATION OF FETUS Perosomus elumbis}

\begin{abstract}
The fetus Perosomus elumbis is inserted in a wide group of rare diseases congenital of etiology unknown in medicine veterinary. Being of low occurrence, hinder study and conclusions about the disease. With maximum survival of two days, being the most of stillbirth fetus, the anomaly is characterized principally by agenesis partial of spinal cord, finishing in the last thoracic vertebrae, and absence of formation of vertebra, diverging to malformation secondary that involve arthrogryposis, atrophy muscular of articulations pelvic and others malformations subsequent. It is also observed the possibility of congenital abnormalities occur concurrently with the formation of these fetuses.
\end{abstract}

KEYWORDS: Agenesis. Congenital. Malformation. Spinal cord.

\section{DESCRIPCIÓN, COMPOSICIÓN Y ASPECTOS ASOCIADOS A LA FORMACIÓN DE FETOS Perosomus elumbis}

RESUMEN: El feto Perosomus elumbis se inserta en una amplia gama de enfermedades congénitas raras y con etiologías desconocidas en Medicina Veterinaria. Debido a su baja incidencia, y de difícil acceso e investigación científica, hay dificultad en realizar estudios y conclusiones acerca de la enfermedad. Con un máximo de supervivencia de dos días, la mayoría de los fetos nacidos muertos, la anomalía se caracteriza principalmente por agenesia parcial de la médula espinal (ausencia o formación incompleta de un órgano), que termina ciegamente en la última vértebra torácica, y ausencia de vértebras lumbares, sacras y coccígeas, que convergen en anomalías secundarias involucrando artrogriposis (flexión o contractura congénita de una articulación), atrofia muscular de miembros pélvicos y otras malformaciones subsecuentes. También se observa la posibilidad de ocurrir anormalidades congénitas concomitantemente a la formación de esos fetos.

PALABRAS CLAVE: Agenesia. Congénita. Malformación. Médula espinal.

\section{Introdução}

A formação dos fetos Perosomus elumbis enquadra em uma classe de doenças congênitas raras e desconhecidas, onde a ocorrência irregular, somada a inexistência de padrões etiológicos e a baixa frequência bibliográfica, impossibilita a realização de pesquisas mais direcionadas ao tema, não havendo uma origem comprovada para a malformação (ARAÚJO et al. 2008). Existem registros da afecção em cães, suínos, ovinos e bovinos, nestes, principalmente nas raças Holandesa e Hereford. E em geral, a presença dos monstros fetais promove a ocorrência de partos distócicos, de acordo com Silva Filho et al. (2015), exigindo a prática de manobras obstétricas como a indução do parto, cesariana ou fetotomia. Considerando na intervenção, a possibilidade de natimortalidade, o que ocorre na maioria dos casos, ou de fetos nascidos vivos com sobrevida máxima de dois dias, quadros resultantes das drásticas alterações neurológicas (GOIOZO, 2005).

As malformações atingem, principalmente, a porção caudal do animal, enquanto a porção cranial apresenta-se em padrões naturais, sendo essas porções unidas apenas por tecidos moles. A severidade da anomalia consiste no término da medula espinhal em fundo cego, na região das últimas

DOI: https://doi.org/10.25110/arqvet.v19i2.2016.5932

${ }^{1}$ Universidade Estadual de Londrina, Acadêmico de Medicina Veterinária, Londrina, Paraná, Brasil.

${ }^{2}$ Universidade Estadual de Londrina, Doutor pelo Programa de Pós Graduação Ciência Animal, Londrina Paraná, Brasil.

*Autor para correspondência: renangmota18@gmail.com 
vértebras torácicas, acompanhada da inexistência de formação óssea das vértebras lombares, sacrais e coccígeas, provocando um encurtamento do corpo do feto (BASILE, 1986; SANTOS, 2013). Há possibilidade de malformações nas últimas vértebras torácicas, prejudicando as estruturas costais mais caudais. Os fetos apresentam artrogripose, e a musculatura dos membros pélvicos encontra-se em estado atrófico (CASTRO, 2008). Observa-se ainda, possíveis disfunções do sistema urogenital e trato intestinal, e malformações na pelve óssea. Ainda de acordo com a literatura há possibilidade de inexistência de cauda (JONES, 1999; GOIOZO, 2005).

As vertentes para a desconhecida origem da anomalia apoiam-se basicamente em duas possibilidades, sendo: efeito teratogênico no período embrionário ou a disfunção na família dos genes Homeobox, responsáveis pela coordenação do desenvolvimento do tubo neural. De acordo com Castro et al. (2008), a hipótese teratogênica fundamenta-se em pesquisas australianas relacionadas à morte de cordeiros recém nascidos apresentando malformações congênitas, em que as mães foram alimentadas com a planta Veratrum californicum (Veratro Branco) entre o $16^{\circ}$ e o $17^{\circ}$ dia de gestação. No sertão brasileiro, há maior incidência de malformações congênitas em cordeiros, cujas mães são alimentadas com uma planta típica usada como forrageira na região, a jurema-preta (Mimosa tenuiflora). (CASTRO, 2008).

A questão envolvendo a família dos genes Homeobox baseia-se na relação entre o controle do desenvolvimento por expressão gênica da família sobre as formações embriológicas da coluna vertebral, do cordão medular e dos tecidos adjacentes, considerando a hipótese de mutação nesses genes (JONES, 1999). Também pode-se citar, as ligações existentes entre o descontrole expressivo dos genes Homeobox na ocorrência de outros padrões disráficos (relacionados ao fechamento anômalo do canal neural), mais conhecidos e com diferentes etiologias e prognósticos, que assim como no Perosomus elumbis, atingem as porções caudais do cordão medular e da coluna vertebral, porém de maneira menos prejudicial (JONES, 1999; GOIOZO, 2005).

Os defeitos morfofisiológicos característicos aos fetos Perosomus elumbis podem apresentar alguma relação com a formação da hidropisia amniótica, também denominada como hidroâmnio, a qual apresenta relatos de envolvimentos com outras afecções do sistema nervoso central, levando em conta assim, a possível disfunção conjunta entre o hidroâmnio e doenças congênitas neurológicas (ROBERTS, 1979). Os casos de hidropsia - acúmulo anormal de fluidos nos tecidos celulares - geralmente ocorrem no último trimestre de gestação, sendo resultado de anomalias fetais que impedem o transporte dos fluídos amnióticos, gerando o acúmulo destes líquidos no saco amniótico.

A hidropsia amniótica é causada por um gene recessivo, que consequentemente aponta para ancestrais portadores da mutação, que por precaução devem ser submetidos a observação ou controle reprodutivo (ROBERTS, 1979). Enquanto isso, para a formação do feto Perosomus elumbis, não há nenhuma indicação preventiva comprovada, devido a não identificação etiológica precisa.

\section{Relato do Caso}

Atendendo a um chamado clínico no Município de Cambé-PR, para procedimento obstétrico em uma fêmea da espécie bovina, raça Nelore, aproximadamente 17 anos de idade, a qual apresentava sinais de distocia, estando gestante de um feto fêmea pesando 22,0 kg. Após avaliar o histórico clínico e submeter a fêmea ao exame físico, foi realizada a palpação retal, levando a suspeita das malformações aqui citadas. Por conseguinte, optando pela manobra obstétrica de remoção manual do feto, foram realizados os procedimentos de tração, seguido de relaxamentos intermitentes para exteriorização do mesmo.

Após a exteriorização do feto, ainda vivo e com respiração superficial e de baixa amplitude, foi detectada a característica anatômica da formação do feto Perosomus elumbis, não havendo existência deformações ósseas vertebrais a partir das últimas, vértebras torácicas e não sendo detectada a presença de cordão medular a partir do mesmo segmento. $\mathrm{O}$ feto apresentava cauda composta apenas por tecidos moles, assim como se fazia na junção das porções cranial e caudal. Constatou-se atrofia muscular evidente nos membros pélvicos e torácicos, artrogripose, anquilose, e as extremidades dos membros pélvicos e torácicos estavam flexionados em desvio do eixo natural na direção caudal (rotacionados lateralmente), caracterizando a presença de artrogripose, ressaltando, que nesse caso, houve comprometimento inclusive, de membros torácicos.

Figura 1: Fêmea bovina da raça Nelore, pesando 22,0 kg após ser removida do canal do parto por manobras obstétricas. Demonstra-se na imagem a rotação dos membros torácicos.

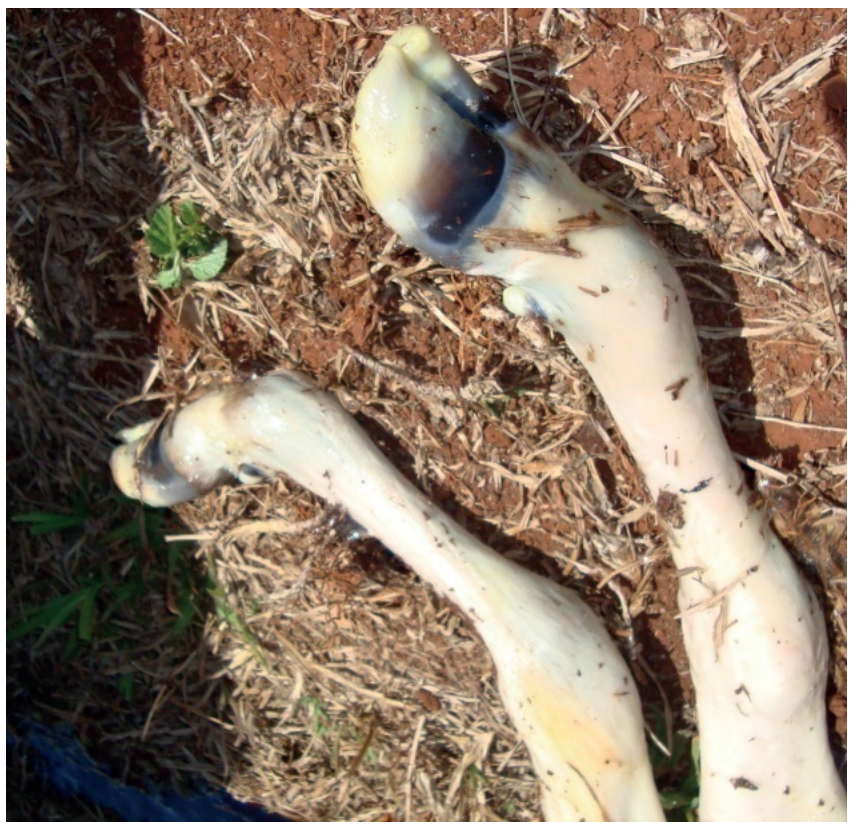

Fonte: Arquivo pessoal, Cambé - PR, 2015. 
Figura 2: A apresentação da composição muscular do membro é indicativa de atrofia, assim como, a rotação caudal evidenciada pela angulção dos cascos, o aumento do volume articular e os defeitos angulares e de conformação, acusam a ocorrencia de artrogripose.

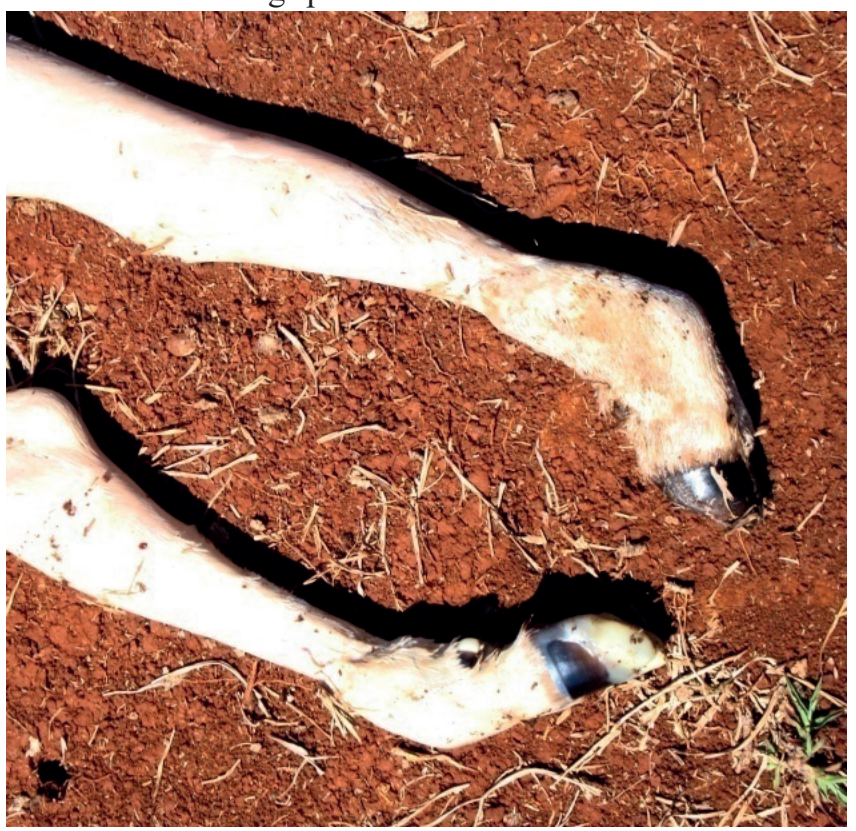

Fonte: Arquivo pessoal,Cambé - PR, 2015

O feto recém-nascido ainda demonstrava aumento turgescente do volume abdominal quando analisado externamente, indicando a ocorrência de hidropisia amniótica. Essa comprovação ocorreu após o derramamento, por meio da liberação de pressão do orifício umbilical, e análise dos fluídos de consistência levemente viscosa e coloração avermelhada, (JACKSON, 2006).

Figura 3: Após aproximadamente 30 minutos, foi determinada a morte do animal, sendo realizada secção em região umbilical para drenagem e exteriorização dos fluidos causadores do aumento de volume.

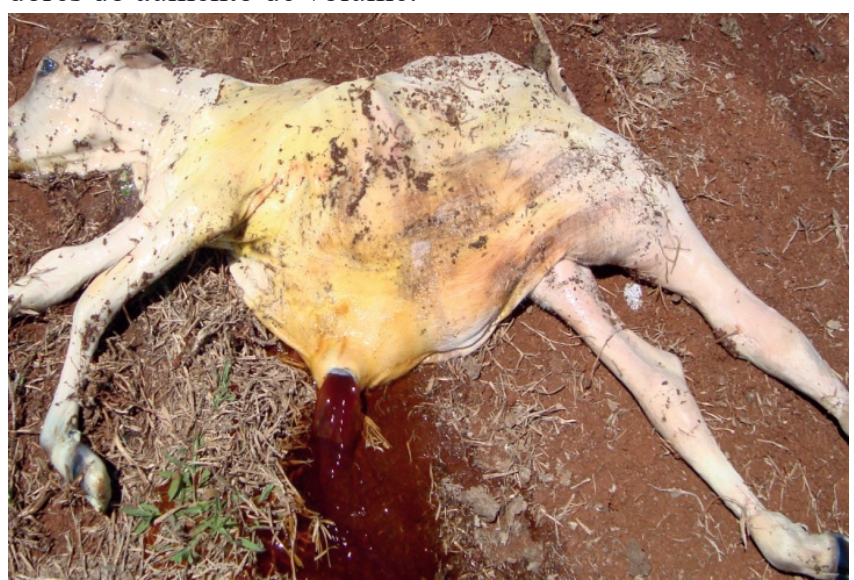

Fonte: Arquivo pessoal, Cambé - PR, 2015.
Figura 4: Imagem da bezerra após a retirada do líquido aminiótico. Destaca-se a flacidez de tecidos cutâneos locais à hidropsia, causada pela turgescência formada pelos fluidos em excesso concentrados na região abdominal.

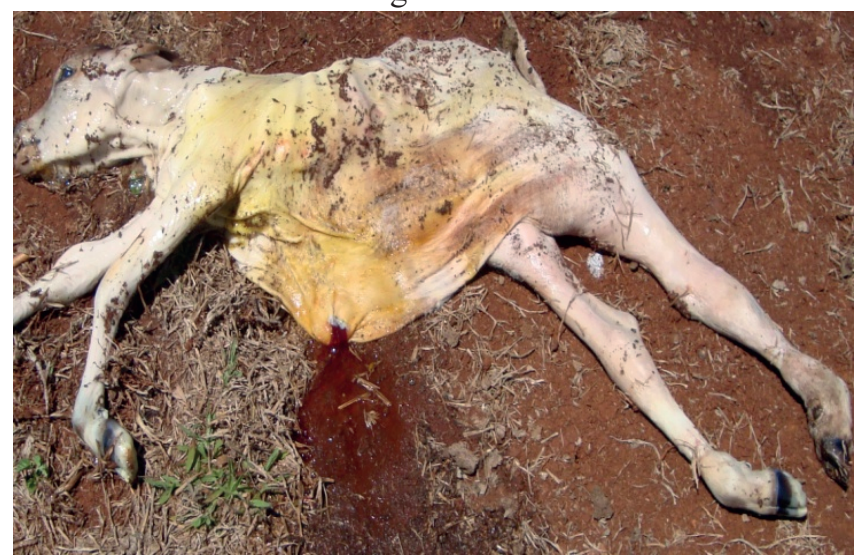

Fonte: Arquivo pessoal, Cambé- PR, 2015.

\section{Discussão}

Em vias de regra, a inexistência de etiologia determinada para a formação da anomalia impede a sua comprovação por exames laboratoriais ou métodos biológicos e moleculares, obtendo o diagnóstico basicamente por meio do histórico da propriedade, exame clínico completo (em casos de sobrevida), e principalmente pela análise das malformações constatadas no animal após a morte, correlacionando-as com as descrições pré-existentes. A partir do quadro existente, o caso foi relacionado ao desenvolvimento do feto Perossomus elumbis, apresentando características de semelhança expressiva para o diagnóstico.

Os sinais característicos do caso são relacionados a ausência de sistema nervoso central na parte caudal do animal (UMARU et al., 2013), promovendo consequentemente as alterações musculoesqueléticas e de nervos periféricos. Portanto, a falha subsequente à indução da malformação pelas possíveis causas citadas, teratogenia ou mutação genética hereditária dos genes Homeobox, estaria relacionada ao fechamento irregular, migração incorreta ou reabertura do tubo neural, ou ainda ao fechamento anormal do sulco neural, segundo García e Fernández (2006), em que a última hipótese justificaria a inexistência da medula espinhal e as anomalias vertebrais adjacentes. Sendo assim, a hipótese para defeito no sulco neural caudal seria a causa direta para as malformações secundárias encontradas nas regiões anatômicas relacionadas ao problema principal, devido a inexistência ou irregularidade do próprio tubo neural, o qual, segundo Kornegay (1986), seria responsável pelo controle de desenvolvimento e formação das vértebras lombares, sacrais e coccígeas, da musculatura ladeada à coluna vertebral e das formações nervosas periféricas englobadas na respectiva localização anatômica. Em síntese, o desenvolvimento correto de todas as estruturas que compõe o sistema nervoso central na porção caudal ou que estão correlacionadas ao mesmo, depende da regularidade do tubo neural.

A perturbação do desenvolvimento fetal e embrionário na existência dos monstros fetais pode levar à hidropsia amniótica, doença que demonstra um aumento lento e progressivo do volume abdominal da fêmea prenhe, podendo assumir eventual aspecto piriforme (REBHUN, 2000). Essa dilatação pode levar a diminuição de apetite, e a dificultar 
respiração e movimentação, tanto pelo esforço necessário mediante ao peso adquirido, quanto pela compressão visceral causada pelo acúmulo de líquido amniótico na região intrauterina. $\mathrm{O}$ animal ainda pode apresentar taquicardia progressiva, ansiedade e, mais raramente, desidratação, metrite e retenção dos anexos fetais no período pós-parto. Como consequência do excesso de peso, pode haver formação de hérnias ventrais e até rompimento do tendão pré-púbico mais raramente. Secundariamente podem ocorrer complicações musculoesqueléticas (luxações, traumatismos, miopatias e outras lesões), devido à fraqueza consequente da má alimentação e ao peso elevado, principalmente quando os diagnósticos e tratamentos ocorrem de maneira tardia. (MCGAVIN; ZACHARY, 2007)

Ao realizar-se a palpação retal, dificilmente será possível a identificação dos cornos uterinos, porém há evidencia tanto do feto quanto dos placentomas. Não existem tendências à alteração das temperaturas padrões a cada categoria, tendo então, a detecção da doença à campo basicamente por observação da distensão abdominal, realização da palpação retal e análise sintomática complementar. Diagnosticada a anomalia, dificilmente o feto apresentará longa sobrevida, evidenciando a tentativa de preservar a fêmea prenhe, partindo então para medidas adequadas à situação, visando à extração do feto e bem estar da fêmea. (ROBERTS, 1979).

Diante dos fatos, as medidas profiláticas tornam-se imprecisas, podendo direcioná-las de acordo com os objetivos de criação da propriedade. Porém, pode ser preconizado o isolamento reprodutivo de acordo com as prioridades particulares de cada proprietário, podendo ou não realizar análises voltadas à determinação do cariótipo dos acometidos ou possíveis portadores da doença que leva à formação do Perosomus elumbis.

\section{Conclusão}

Assim, determinadas as doenças congênitas causadoras do parto distócico e da consequente morte do neonato, buscou-se realizar a descrição do relato ocorrido, com o objetivo de acrescentar às bibliografias anteriores referentes ao tema decorrido nesse artigo. Levando em conta a não existência etiológica comprovada da formação dos fetos Perosomus elumbis e a raridade de relatos desse caso principalmente no Brasil e em gado zebuíno, teve-se também como escopo auxiliar na caracterização da anomalia congênita, visando facilitar a definição e a descrição de possíveis casos futuros, assim como difundir e tornar conhecida a possibilidade da anomalia e seus possíveis aspectos correlacionados.

\section{Referências}

ARAÚJO, B. M. et al. Perosomus elumbis em cão Beagle. Ciência Veterinária nos Trópicos, Recife, v. 11, n. 1, p. 36-39, 2008.

BASILE, B. H. et al. Perosomus elumbis em bovinos. Semina: Ciências Agrárias, Londrina, v.7 (especial), p. 44-46, 1986.

CARLTON, W. W.; MCGIVEN, D. M. Patologia

Veterinária Especial de Thomson, $2^{\mathrm{a}}$ Edição. São Paulo:

Artmed, 1998, p. 674.
CASTRO, M. B. et al. Perosomus elumbis em um cordeiro no Brasil. Ciência Rural, Santa Maria, v. 38, n. 1, p.262265,2008

SILVA FILHO, A. P. et al. Monstros Fetais Como Causa de Distocias em Vacas. Revista Brasileira de Ciências Veterinárias, Niterói, v. 22, n. 2, p. 81-84, 2015.

GARCIA, S. M. L.; FERNÁNDEZ, C. G. Embriologia. $2^{\text {a }}$ Ed. Porto Alegre: Artmed, 2006.

GERHAUSER, I.; GEBUREK, F.; WOHLSEIN, P.

Perosomus elumbis - cerebral aplasia and spina bifida in an aborted thorough bred foal. PubVet, v. 92, n. 2, p. 266-268, 2012.

GOIOZO, P. F. et al. Perosomus elumbis em bovino. Revista de Educação Continuada em Medicina Veterinária, CRMV/SP, São Paulo, v. 8, n. 2, p. 164-167, 2005.

GRUNERT, E.; BOVE, S.; STOPIGLIA, A. V. Obstetrícia Veterinária. $2^{\mathrm{a}}$ Ed. Porto Alegre, 1973.

JACKSON, P. G. G. Obstetrícia Veterinária. $2^{\mathrm{a}}$ Ed.. São

Paulo: Editora Roca, 2006. 314p. p.24.

JONES, C. J. Perosomus elumbis (vertebral agenesis and arthrogryposis) in a Stellborn Holstein calf. Veterinary Pathology, v. 36, p. 64 - 70, 1999.

KORNEGAY, J. N. Neurologic disorders. New York: Churchill Livingstone, 1986.

LAHUNTA, A.;D.V.M. Veterinary neuroanatomy and clinical neurology. Second Edition. Philadelphia, W. B. Saunders Company, 1983.

MCGAVIN, M. D.; ZACHARY, J. F. Pathologic basis of veterinary disease. Fourth Edition. Mosby: Elservier, 2007.

REBHUN, W. C. Doenças do Gado Leiteiro. São Paulo: Roca, p. 642, 2000.

ROBERTS, S. J. D.V.M. Obstetrícia veterinária y patologia de la reproducion (Teriogenologia). Buenos Aires: Hemisferiosur, 1979.

SANTOS, C. R. et al. Perossomus elumbis em bovinos. Pub Vet, Londrina, v. 7, n. 23, p. 01 - 04, 2013.

SON, J. M. et al. A case of Perosomus elumbis ia Holfstein calf. Journal of Veterinary Medical Science, v. 70, n. 5, p. $521-523,2008$

UMARU, M.A. et al. Perosomus elumbis in a day old udah neonate lamb in Sokoto, Nigeria. Scientific Journal of Zoology. Nigáeria, v.2, n.1, p.12-14, 2013. 